\title{
Role of Mind Diet in Preventing Dementia and Alzheimers Disease
}

\author{
Swatilekha Roy Sarkar ${ }^{1}$, Rajib Dutta ${ }^{2 *}$

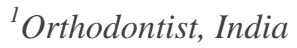 \\ ${ }^{2} \mathrm{MD}$, Neurology, India
}

\author{
*Corresponding Author: Rajib Dutta, MD, Neurology, India, Email: rajibdutta@163.com
}

\begin{abstract}
There is sufficient epidemiological evidence to suggest a strong correlation exists between diet, lifestyle, psychosocial factors, education, cardiovascular risk factors and the onset and consolidation of dementia and Alzheimer's disease (AD). Researchers has shown AD, diabetes, obesity, insulin resistance, and cardiovascular disease, hypercholesterolemia are strongly interrelated pathologies. Dementia is a global concern, placing a significant financial burden on patients, carers, and health care systems. Since its discovery almost a century ago, $A D$ is still considered as an eminent cause of irreversible form of dementia in aging population and developed countries. Considering the absence of available disease-modifying therapies for dementia and $A D$ treatment, there is a great need in preventing and delaying the onset of cognitive impairment in healthy older subjects. Strategies to delay metabolic, vascular risk burden and introducing nutritional interventions seem to be promising approaches to delay neurocognitive decline and reduce the risk of $A D$ and other non-psychiatric co-morbidities. However the role of diet in cognitive health, mental well being and prevention of dementia in older adults is being extensively studied. Here we review the role of MIND (Mediterranean-DASH diet intervention for neurodegenerative delay) diet which has recently gained much attention due to its beneficial effects associated with overall diet composition, for the delay of dementia and $A D$.
\end{abstract}

Keywords: Diet; MIND; Cognitive decline; Cognitive impairment; Cognition; Healthy food, Alzheimer's disease.

\section{INTRODUCTION}

Alzheimer's disease (AD) is a neurodegenerative disorder clinically characterized by cognitive and behavioral impairment. It is progressive and currently incurable with a long presymptomatic period and is expected to increase in the coming decades due to progressive ageing of the world population [1]. Each year there are 9.9 million new cases of dementia worldwide, equal to about one new case diagnosed every $3.2 \mathrm{~s}$ [2]. In 2015, approximately 47 million people worldwide were diagnosed with dementia, which is the seventh leading cause of death worldwide [3]. AD is a disease of later life, affecting one in four people 85 years of age or over, and the incidence is expected to rise in the coming years, with 131.5 million estimated cases by 2050 [4]. Apart from the burden directly linked with this progressive neurodegenerative condition, health care costs are increasing exponentially over time [5]. By delaying the disease onset by 5 years is enough to reduce the health expenditure and prevalence by half [6].
Increasing evidence indicates that the pathological hallmark of the disease [e.g., amyloid beta $(\mathrm{A} \beta)$ plaques and neurofibrillary tangle (NFT) formation] start appearing several decades before the onset of clinical symptoms $[7,8]$ which is also known as pre clinical phase of $\mathrm{AD}$ where we can try preventive strategies to delay the process of cognitive decline. The apolipoprotein E $\varepsilon 4$ (ApoE $\varepsilon 4$ ) allele has been shown to be a major genetic risk factor for more rapid cognitive decline and earlier onset of $\mathrm{AD}$ $[9,10]$. Metabolic syndrome (MetS) which includes diabetes, hypertension, obesity, high cholesterols, insulin resistance and cardiovascular disease are deeply interconnected with AD pathology [11]. Insulin resistance and high levels of plasma homocysteine, which represent MetS-related risk factors, have a major impact on cerebral physiology and morphology, $\mathrm{A} \beta$ deposition and build-up of neuritic plaques [12]. Impairment of mitochondrial metabolism pathways and decrease in ATP production causes neuronal injury and represents an early 
event in the progression of $\mathrm{AD}[13,14]$. Nonglycosylated full length and C-terminal truncated $\mathrm{A} \beta$ precursor protein (APP) have been found to accumulate in neuronal mitochondria in $\mathrm{AD}$ affected subjects [15]. $\mathrm{A} \beta$ overproduction causes mitochondrial damage, dysfunction of mitochondrial complexes I and IV, increase of reactive oxygen species, and depletion of adenosine triphosphate (ATP), which in neurons may lead to neurotransmission and axonal transport impairment and degeneration [16]. In summary the neuropathology and etiology of $\mathrm{AD}$ indicate that a complex series of molecular mechanisms is involved, including the amyloid hypothesis, abnormal mitochondrial function, oxidative stress, formation of reactive oxygen species, and neuroinflammation as the important mainstream molecular pathways. In turn, the neuroinflammatory cascade may be synergistically associated with immunosenescence and gut dysbiosis, intercepting the trajectories of the aging brain and the progression to dementia.

Whole brain atrophy rates range from 0.3 to $0.7 \%$ per year in healthy older adults [17]. Hippocampal volume decreases at a rate of $2-4 \%$ per annum in healthy aged individuals [18]. On contrary MRI in $\mathrm{AD}$, reveals widespread cortical atrophy, particularly within medial temporal lobe structures including the amygdala, hippocampus, and parahippocampal gyrus [19], with whole brain atrophy rates ranging from 1 to $4 \%$ per year [17]. FDG-PET studies have shown that between 20 and 70 years of age, global cerebral metabolic rate decreases by $12-13 \%$ [20]. Pittsburgh Compound B (PiB)-PET is used to visualise and quantify deposition of the protein beta-amyloid $(A \beta)$ within the living brain. Elevated levels of cerebral $A \beta$ in apparently healthy persons are found in $12 \%$ of those in their 60 s, $30 \%$ of those in their 70 s, and at least $50 \%$ of those over 80 years of age. Moreover, PiB-PET determined cerebral A $\beta$ levels correlate with rate of memory decline in healthy older adults consistent with the notion that $A \beta$ accumulation promotes neuronal death, which ultimately results in cognitive impairment [21].

Most healthy adults experience age related decline in a variety of cognitive domains including spatial orientation, episodic memory, speed of processing, language, decision-making abilities, judgment, and abstract thinking [22]. Subjective memory complaints (SMC) represent self-identified changes in memory and are strongly associated with ageing [23, 24]. They may be considered as an early marker of subsequent cognitive decline in multiple domains, and are a possible precursor of mild cognitive impairment (MCI) and neurodegenerative disease such as Alzheimer disease (AD) and dementia [24-27]. Elevated levels of cortisol and lower levels of estrogen and testosterone have all been associated with the development of dementia [28-30]. Assessment of thyroid stimulating hormone levels is considered a standard screening test for the diagnosis of dementia, as both hyper and hypothyroidism can interact with brain metabolism and if found can be reversible [31].

Altogether, all these studies indicate that complex systemic, metabolic, and endocrine mechanisms are responsible in the etiopathogenesis of dementia and AD. Adding nonpsychiatric comorbidities to a wide spectrum of MetSassociated illness plus cardiovascular ailments, it is possible that nutritional patterns and habits may play a great role in the onset of cognitive decline and $\mathrm{AD}$ in different geographical location and population. With lot of epidemiological evidence in previous studies, researchers in this field suggest that modifiable lifestyle factors, including diet, could play an important role in maintaining brain and cognitive health. A healthy diet characterized by high consumption of plant foods, whole grains, olive oil and fish, and ensuring an adequate intake in various vitamins (vit A,B,C,D,E) and minerals could help to strengthen cognitive abilities by stimulating memory [32,33].

Plant-based, healthy dietary interventions have shown promising results also for the amelioration of gut dysbiosis [34], which has been associated with the etiopathogenesis of $\mathrm{AD}$ and amyloid formation [35,36]. In particular, the Mediterranean Diet (MD) has been associated with a better cognitive function and a lower risk of cognitive impairment, $\mathrm{AD}[37,38$,] and subjective cognitive function [39]. The Dietary Approaches to Stop Hypertension (DASH), initially designed to reduce elevated blood pressure, has also been associated with a better cognitive function in a number of studies [40-42].

Recently, a new concept of diet aimed at protecting the brain, namely the MIND diet, was developed [43]. The MIND diet includes many dietary components from the MD and DASH, as well as specific components such as green leafy vegetables and berries known for their neuroprotective role [44]. The MIND diet score was found to be a better predictor of cognitive 
decline than either the MD or DASH diet scores in the Rush Memory and Aging Project [43]. Studies has showed that adherence to the MIND diet was associated with a better cognitive heath $[43,45,46]$ and a lower risk of $\mathrm{AD}[47]$.

MIND diet is a mix of components of the MD and the DASH diet, with some modifications to optimize brain health. It includes ten "brain healthy" food groups (green leafy vegetables, other vegetables, nuts, berries, and beans, whole grains, fish, poultry, olive oil, and wine) and five unhealthy food groups (red meats, butter and margarine, cheese, pastries and sweets, and fast fried foods) [43]. Adjibade et al., reported beneficial effect of the MIND diet on subjective memory complaint(SMC)and cognitive functions or dementia could be attributed to healthy components such as vegetables (especially green leafy vegetables), nuts, berries, beans, whole grains, fish, poultry, olive oil, and wine. Indeed, healthy foods accounted in the MIND diet provide high amounts of several nutrients, including carotenoids, vitamins $\mathrm{B}, \mathrm{C}, \mathrm{D}, \mathrm{E}$, and polyphenols [43, 44, 45]. Most of these nutrients have been shown to have anti-inflammatory properties and are required for normal physiological functioning of the brain $[46,48,49]$. Dietary fibers also play an important role in cognition, in particular via their influence on gut microbiota composition [50, 51].

Previous studies, including the milestone Rotterdam study, have pointed out the relevance of nutrition in counteracting brain neurodegeneration [52]. Although several nutritional approaches have been considered as possible alternatives like low GI diet, Prudent healthy diet, Anti inflammatory diet to the currently existing drugs for $\mathrm{AD}$, this line of research has only been partially explored and has not resulted in any solid evidence $[53,54,56]$. It is possible that most of the studies are done in USA till date with little evidence from other parts of the world like south East Asia, Africa etc. Recent advances has indicated that epigenetics can throw some light on our current understanding based on imaging , CSF markers, neuropathology on such a complex neuro-degenerative pattern. DNA methylation, histone modifications, and micro RNAs are the principal epigenetic mechanisms involved in AD pathophysiology [55,57,58]. Nutrition is now believed by many workers to be a modifiable factor that seems to strongly impact on $A D$ pathology by modulating its phenotypic expression [57, 58].

\section{DISCUSSION}

Etiopathogenesis of dementia and AD is very complex. Currently available pharmacological treatments for $\mathrm{AD}$ and dementia can only temporarily stabilize symptoms in a minority of patients, without effects on long-term prognosis or survival. The clinical evidence that has been collected in recent years for DASH, MD, and more recently MIND able to modify the natural history of neurodegenerative pathologies, in particular $\mathrm{AD}$, thereby preventing their development or slowing down their progression. The strength of these dietary approaches lies in their multifactorial composition. In fact, nutrient-dense foods can interact with each other with potentially synergistic effects on different metabolic and cellular signaling pathways, leading to neuroprotection and maintaining health of individual neurons .But there are considerable methodological difficulties in conducting in vitro and in vivo studies to document the effects of such dietary patterns on the brain, due to the intrinsic complexity of a whole diet, the micro- and macronutrient composition, the importance of food cooking methods, and unavailibilty in different geographical areas.

Animal studies suggest possibility that these dietary patterns might influence $\mathrm{A} \beta$ or Tau metabolism, and require further assessment and confirmation [59, 60]. At a systemic level, they can also indirectly improve cognition by reducing cardiovascular risk factors such as lipid levels, blood glucose, and blood pressure [61, 62]. The core mechanisms studied extensively till date are neurovascular dysfunctions [63-67], oxidative stress [68-74], neuroinflammation [75-79], gut microbiota dysbiosis [80-84], adult hippocampal neurogenesis [85-87]. A few recent studies, however, have suggested that the prevalence of dementia might be subject to change over time and that in higher income countries, both its prevalence and incidence might have decreased over the past two decades [88-90], owing to improved prevention of vascular morbidity and higher levels of education [88].

With regards to nutrition, attention to overall diet composition rather than single nutrient supplementations seems to be a more sound and effective approach for the prevention and management of $\mathrm{AD}$ risk, in light of the fact that nutrients present in foods synergistically interact with each other may it be macro or micro nutrient. High adherence to healthful dietary patterns MIND diet in particular, has shown to 
be associated with lower rates of cognitive decline and reduced risk of developing dementia and $\mathrm{AD}$ [46,91-97], Hosking et al recently reported cognitively protective effects of the MIND diet generalize to a population outside the United States also and greater MIND diet adherence was associated with 19\% reduced odds of developing clinically diagnosed $\mathrm{MCI} /$ dementia after 12-years of follow-up and with $53 \%$ reduction in the odds of impairment.

\section{CONCLUSION}

As we have discussed in our review dementia and particularly $\mathrm{AD}$ has many interlinked risk factors, it is hardly possible to control all of them together at a point of time so preventive strategy is must. There is strong epidemiological evidence for a protective role of the neuroprotective dietary patterns on cognitive decline and dementia in older persons. Crosscountry variation in food supply, dietary behaviors, and other lifestyle factors determine the generalizability of dietary effects on risk for cognitive impairment and dementia. Enthusiam of MIND diet has led researchers to test it in post a stroke patient who slows cognitive decline (98) and Parkinsons disease (PD) where it reduced and delayed progression of parkinsonism in old age [99]. Dietary patterns in early onset dementia remains unknown. Clearly, more studies are required in future in other populations and geographic locations to further evaluate the protective effects.

\section{ACKNOWLEDGEMENT}

The author has no relevant affiliations or financial involvement with any organization or entity with a financial interest in or financial conflict with the subject matter or materials discussed in the manuscript. Special thanks to my supervisor Professor Dr. Huifang Shang who gave initial ideas and supported me through this research study. I would also like to thank Dr. Swatilekha RoySarkar for her valuable feedback on the manuscript and literature screening from PubMed.

\section{REFERENCES}

[1] Alzheimer's Association (2016) 2016 Alzheimer's disease 1191 facts and figures. Alzheimers Dement 12, 459-509.

[2] A.s.D, International Dementia Statistics, (2018) https://www.alz.co.uk/research/statisticsm (Acc essed ecember 9, 2017).

[3] WHO. Global Health Observatory (GHO) data: top 10 causes of death .2017[ last accessed 19 Feb 2018]. Available from: http://www.who. int/gho/mortality_burden_disease/causes_death / top_10/en/.

[4] Alzheimer's disease International, "World Alzheimer report 2015," The Global Economic Impact of Dementia, 2015.

[5] A. Wimo, L. Jonsson, J. Bond, M. Prince, B. Winblad, I. Alzheimer disease, the worldwide economic impact ofdementia 2010, Alzheimer's Dement. 9 (2013) 1-11 (e13).

[6] Prince M, Wimo A, Guerchet $M$, et al. Changing the trajectory of AD: how a treatment by 2025 saves lives and dollars. 2015. https://www.alz.co.uk/research/WorldAlzheime rReport2015.pdf. [Accessed 15 June 2017].

[7] R.A. Sperling, P.S. Aisen, L.A. Beckett, D.A. Bennett, S. Craft, A.M. Fagan, T. Iwatsubo, C.R. Jack, Jr., J. Kaye, T.J. Montine, D.C. Park, E.M. Reiman, C.C. Rowe, E. Siemers, Y. Stern, K. Yaffe, M.C. Carrillo, B. Thies, M. MorrisonBogorad, M.V. Wagster, C.H. Phelps, Toward defining the preclinical stages ofAlzheimer's disease: recommendations from the National Institute on Aging-Alzheimer's Association workgroups on diagnostic guidelines for Alzheimer's disease, Alzheimer's \& Dement. 7 (2011) 280-292.

[8] M.W. Schelke, K. Hackett, J.L. Chen, C. Shih, J. Shum, M.E. Montgomery,G.C. Chiang, C. Berkowitz, A. Seifan, R. Krikorian, R.S. Isaacson, Nutritional interventions for Alzheimer's prevention: a clinical precision medicine approach,Ann. N. Y. Acad. Sci. 1367 (2016) 50-56.

[9] Corder, E., Saunders, A., Strittmatter, W., Schmechel, D., Gaskell, P., Small, G., PericakVance, M. (1993). Gene dose of apolipoprotein E type 4allele and the risk of Alzheimer's disease in late onset families. Science, 261(5123), 921-923. doi:10.1126/scie nce.834 6443

[10] Wilson RS, Schneider JA, Barnes LL, Beckett LA, Aggarwal NT, Cochran EJ, et al. The apolipoprotein E epsilon 4 allele and decline in different cognitive systems during a 6-year period. Arch Neurol. 2002;59(7):1154-60

[11] F. Pistollato, M. Battino, Role of plant-based diets in the prevention and regression of metab olic syndrome and neurodegenerative diseases, Trends Food Sci. Technol.40 (2014) 62-81.

[12] H.J. Milionis, M. Florentin, S. Giannopoulos, Metabolic syndrome and Alzheimer's disease: a link to a vascular hypothesis? CNS Spectr. 13 (2008) 606-613.

[13] S.J. Baloyannis, Mitochondrial alterations in Alzheimer's disease, J. Alzheimers Dis. 9 (2006) 119-126.

[14] P. Picone, D. Nuzzo, L. Caruana, V. Scafidi, M. Di Carlo, Mitochondrial dysfunction:different routes to Alzheimer's disease therapy, Oxid. Med. Cell Longev. 2014 (2014) 780179. 
[15] L. Devi, B.M. Prabhu, D.F. Galati, N.G. Avadhani, H.K. Anandatheerthavarada, Accumulation of amyloid precursor protein in the mitochondrial import channelsof human Alzheimer's disease brain is associated with mitochondrial dysfunction, J. Neurosci. 26 (2006) 9057-9068

[16] H. Du, L. Guo, S. Yan, A.A. Sosunov, G.M. McKhann, S.S. Yan, Early deficits insynaptic mitochondria in an Alzheimer's disease mouse model, Proc. Natl. Acad. Sci. U. S. A. 107 (2010) 18670-18675

[17] Cover KS, van Schijndel RA, van Dijk BW, Redolfi A, Knol DL, Frisoni GB, et al. Assessing the reproducibility of the SienaX and Siena brain atrophy measures using the ADNI back-to-back MPRAGE MRI scans. Psychiatry Res. 2011;193(3):182-90.

[18] Raz N, Lindenberger U, Rodrigue KM, Kennedy KM, Head D, Williamson A, et al. Regional brain changes in aging healthy adults: general trends, individual differences and modifiers. Cereb Cortex. 2005;15(11):1676-89.

[19] Jobst KA, Smith AD, Szatmari M, Molyneux A, Esiri ME, King E, et al. Detection in life of confirmed Alzheimer's disease using a simple measurement of medial temporal lobe atrophy by computed tomography. Lancet. 1992;340 (8829):1179-83.

[20] Berti V, Mosconi L, Pupi A. Brain: normal variations and benign findings in fluoride oxyglucose-PET/computed tomographyimag ng. PET Clin. 2014;9(2):129 - 40.

[21] Rowe CC, Villemagne VL. Brain amyloid imaging. J Nucl Med. 2011;52(11):1733-40.

[22] Tucker-Drob EM, Reynolds CA, Finkel D, Pedersen NL. Shared and unique genetic and environmental influences on aging-related changes in multiple cognitive abilities. Dev Psychol. 2014;50(1): 152-66

[23] Balash Y, Mordechovich M, Shabtai H et al (2013) Subjective memory complaints in elders: depression, anxiety, or cognitive decline? Acta Neurol Scand 127:344-350. https ://doi.org/10. $1111 /$ ane. 12038

[24] Jonker C, Geerlings MI, Schmand B (2000) Are memory complaints predictive for dementia? A review of clinical and population- based studies. Int J Geriatr Psychiatry 15:983-991

[25] Mitchell AJ, Beaumont H, Ferguson D et al (2014) Risk of dementia and mild cognitive impairment in older people with subjective memory complaints: meta-analysis. Acta Psychiatr Scand 130:439-451.https://doi.org/1 0.1111/acps. 12336

[26] Kaup AR, Nettiksimmons J, LeBlanc ES, Yaffe K (2015) Memory complaints and risk of cognitive impairment after nearly 2 decades among older women. Neurology 85:1852-1858.
https://doi.org/10.1212/WNL.00000000000021 53.

[27] Brigola AG, Manzini CSS, Oliveira GBS et al (2015) Subjective memory complaints associated with depression and cognitive impairment in the elderly: a systematic review. Dement Neuropsychol 9: 9:51-57. https://doi. org/10.1590/S1980 -57642 015DN 91000009.

[28] J.G. Csernansky, H. Dong, A.M. Fagan, L. Wang, C. Xiong, D.M. Holtzman,J.C. Morris, Plasma cortisol and progression of dementia in subjects with Alzheimer-type dementia, Am. J. Psychiatry 163 (2006) 2164-2169.

[29] S.A. Shumaker, C. Legault, S.R. Rapp, L. Thal, R.B. Wallace, J.K. Ockene, S.L. Hendrix, B.N. Jones 3rd, A.R. Assaf, R.D. Jackson, J.M. Kotchen,S. Wassertheil-Smoller, J. WactawskiWende, W. Investigators, Estrogen plus progestin and the incidence of dementia and mild cognitive impairment in post menopausal women: the Women's Health Initiative Memory Study: a randomizedcont rolled trial, JAMA 289 (2003) 2651-2662.

[30] S. Suravarapu, E.J. Bergstralh, S.A. Farmer, D.S. Knopman, S.J. Jacobsen,R.O. Roberts, Dementia and low testosterone and bioavailable testosterone levels in men: possible increased risk, Alzheimer Dis. Assoc. Disord. 20 (2006) 138-140.

[31] D.S. Knopman, S.T. DeKosky, J.L. Cummings, H. Chui, J. Corey-Bloom, N. Relkin, G.W. Small, B. Miller, J.C. Stevens, Practice parameter: diagnosis of dementia (an evidencebased review). Report of the Quality Standards Subcommittee of the American Academy of Neurology, Neurology 56 (2001) 1143-1153.

[32] Abate G, Marziano M, Rungratanawanich W et al (2017) Nutrition and AGE-ing: focusing on Alzheimer's disease. Oxid Med Cell Longev 2017:7039816. https://doi.org/10.1155/2017/70 39816.

[33] Smith PJ, Blumenthal JA (2016) Dietary factors and cognitive decline. J Prev Alzheimers Dis 3:53-64. https://doi.org/10.14283/jpad.2015.71.

[34] M.S. Kim, S.S. Hwang, E.J. Park, J.W. Bae, Strict vegetarian diet improves the risk factors associated with metabolic diseases by modulating gut microbiota and reducing intestinal inflammation, Environ. Microbiol. Rep. 5 (2013) 765-775.

[35] F. Pistollato, S. Sumalla Cano, I. Elio, M. Masias Vergara, F. Giampieri, M. Battino, Role of gut microbiota and nutrients in amyloid formation and pathogenesis of Alzheimer disease, Nutr. Rev. 74 (2016) 624-634.

[36] X. Hu, T. Wang, F. Jin, Alzheimer's disease and gut microbiota, Sci. China Life Sci. 59 (2016) 1006-1023.

[37] Wu L, Sun D (2017) Adherence to Mediterranean diet and risk of developing 
cognitive disorders: an updated systematic review and meta-analysis of prospective cohort studies. Sci Rep 7:41317. https://doi.org/10. 1038/srep4 1317.

[38] Aridi YS, Walker JL, Wright ORL (2017) The association between the mediterranean dietary pattern and cognitive health: a systematic review. Nutrients. https://doi.org/10.3390/nu9 070674.

[39] Bhushan A, Fondell E, Ascherio A et al (2017) Adherence to Mediterranean diet and subjective cognitive function in men. Eur $\mathrm{J}$ Epidemiol. https://doi.org/10.1007/s1065 4-017-0330-3.

[40] Tangney CC, Li H, Wang Y et al (2014) Relation of DASH- and Mediterranean-like dietary patterns to cognitive decline in older persons. Neurology 83:1410-1416. https://doi. org/10.1212/ WNL.00000 00000000884.

[41] Berendsen AAM, Kang JH, van de Rest O et al (2017) The dietary approaches to stop hypertension diet, cognitive function, and cognitive decline in american older women. $\mathbf{J}$ Am Med Dir Assoc 18:427-432. https://doi. org/10.1016/j.jamda .2016.11.026.

[42] Wengreen H, Munger RG, Cutler A et al (2013) Prospective study of dietary approaches to stop hypertension- and mediterranean style dietary patterns and age-related cognitive change: the Cache County Study on Memory, Health and Aging. Am J Clin Nutr 98:1263-1271. http s://doi.org/10.3945/ajcn.112.05127 6.

[43] Morris MC, Tangney CC, Wang Y et al (2015) MIND diet slows cognitive decline with aging. Alzheimers Dement J Alzheimers Assoc 11:10 15-1022. https://doi.org/10.1016/j.jalz.2015.04. 011.

[44] Morris MC (2016) Nutrition and risk of dementia: overview and methodological issues. Ann N Y Acad Sci 1367:31-37. https://doi.org / 10.1111/nyas. 13047.

[45] Vauzour D, Camprubi-Robles M, MiquelKergoat $S$ et al (2017) Nutrition for the ageing brain: Towards evidence for an optimal diet. Ageing Res Rev 35:222-240. https://doi.org/ 10.1016/j. arr.2016.09.010.

[46] Solfrizzi V, Custodero C, Lozupone $\mathrm{M}$ et al (2017) Relationships of dietary patterns, foods, and micro- and macronutrients with Alzheimer's disease and late-life cognitive disorders: a systematic review. J Alzheimers Dis JAD 59:815-849. https://doi.org/10.3233/ JAD-17024 8.

[47] Meeusen R (2014) Exercise, nutrition and the brain. Sports Med Auckl NZ 44(Suppl 1):S47S56. https://doi.org/10.1007/s40279-014-0150 -5.

[48] Del Parigi A, Panza F, Capurso C, Solfrizzi V (2006) Nutritional factors, cognitive decline, and dementia. Brain Res Bull 69:1-19. http s://doi.org/10.1016/j.brain resbu 11.2005.09. 020.
[49] Solfrizzi V, Panza F, Capurso A (2003) The role of diet in cognitive decline. J Neural Transm Vienna Austria 1996 110:95-110. https://doi.org/10.1007/s0070 2-002-0766-8.

[50] T. Harach, N. Marungruang, N. Duthilleul et al., "Reduction of Abeta amyloid pathology in APPPS1 transgenic mice in the absence of gut microbiota," Scientific Reports, vol. 7,no. 1, article 41802, 2017.

[51] Simpson HL, Campbell BJ (2015) Review article: dietary fibre microbiota interactions. Aliment Pharmacol Ther 42:158-179. https:// doi.org/10.1111/apt.13248.

[52] M. D. M. Haag, A. Hofman, P. J. Koudstaal, B. H. C. Stricker, and M. M. B. Breteler, "Statins are associated with a reduced risk of Alzheimer disease regardless of lipophilicity. The Rotterdam study," Journal of Neurology, Neurosurgery \& Psychiatry, vol. 80, no. 1, pp. 13-17, 2009.

[53] E. M. van der Beek and P. J. G. H. Kamphuis, "The potential role of nutritional components in the management of Alzheimer's disease," European Journal of Pharmacology, vol. 585, no. 1, pp. 197-207, 2008.

[54] L. Nelson and N. Tabet, "Slowing the progression of Alzheimer's disease; what works?," Ageing Research Reviews, vol. 23, pp. 193-209, 2015.

[55] S. J. Shewale, R. M. Huebinger, M. S. Allen, and R. C. Barber, "The potential role of epigenetics in Alzheimer's disease etiology," Biological Systems: Open Access, vol. 2, no. 3, p. 114, 2013

[56] S. S. M. Fernández and S. M. L. Ribeiro, "Nutrition and Alzheimer disease," Clinics in Geriatric Medicine, vol. 34, no. 4,pp. 677-697, 2018.

[57] D. Athanasopoulos, G. Karagiannis, and M. Tsolaki, "Recent findings in Alzheimer disease and nutrition focusing on epigenetics," Advances in Nutrition, vol. 7, no. 5, pp. 917927, 2016.

[58] V. Nicolia, M. Lucarelli, and A. Fuso, "Environment, epigenetics and neurodegener ation: focus on nutrition in Alzheimer's disease," Experimental Gerontology, vol. 68, pp. 8-12, 2015.

[59] L. Fernández-Fernández, G. Comes, I. Bolea et al., "LMN diet, rich in polyphenols and polyunsaturated fatty acids, improves mouse cognitive decline associated with aging and Alzheimer's disease," Behavioural Brain Research, vol. 228, no. 2, pp. 261-271, 2012.

[60] C. Grossi, S. Rigacci, S. Ambrosini et al., "The polyphenololeuropein aglycone protects TgCRND8 mice against Aß plaque pathology," PLoS One, vol. 8, no. 8, article e71702, 2013.

[61] C. Razquin, E. Toledo, C. B. Clish et al., "Plasma lipidomic profiling and risk of type 2 
diabetes in the PREDIMED trial," Diabetes Care, vol. 41, no. 12, pp. 2617-2624, 2018.

[62] P. Saneei, A. Salehi-Abargouei, A. Esmaillzadeh, and L. Azadbakht, "Influence of Dietary Approaches to Stop Hypertension (DASH) diet on blood pressure: a systematic review and meta-analysis on randomized controlled trials," Nutrition, Metabolism and Cardiovascular Diseases, vol. 24, no. 12, pp. 1253-1261, 2014.

[63] Z. Arvanitakis, A. W. Capuano, S. E. Leurgans, D. A. Bennett, and J. A. Schneider, "Relation of cerebral vessel disease to Alzheimer's disease dementia and cognitive function in elderly people: a cross-sectional study," The Lancet Neurology, vol. 15, no. 9, pp. 934-943, 2016.

[64] K. Kisler, A. R. Nelson, A. Montagne, and B. V. Zlokovic, "Cerebral blood flow regulation and neurovascular dysfunction in Alzheimer disease," Nature Reviews Neuroscience, vol. 18, no. 7, pp. 419-434, 2017.

[65] S. P. Didion, C. D. Sigmund, and F. M. Faraci, "Impaired endothelial function in transgenic mice expressing both human renin and human angiotensinogen," Stroke, vol. 31, no. 3, pp. 760-765, 2000.

[66] M. Wiesmann, C. Capone, V. Zerbi et al., "Hypertension impairs cerebral blood flow in a mouse model for Alzheimer'sdisease," Current Alzheimer Research, vol. 12, no. 10, pp. 914922, 2015.

[67] N. D. L. Fisher, F. A. Sorond, and N. K. Hollenberg,"Cocoa flavanols and brain perfu sion," Journal of Cardiovascular Pharmacology, vol. 47, Supplement 2, pp. S21 0- S214, 2006.

[68] F. di Domenico, G. Pupo, E. Giraldo et al., "Oxidative signature of cerebrospinal fluid from mild cognitive impairment and Alzheimer disease patients," Free Radical Biology \& Medicine,vol. 91, pp. 1-9, 2016.

[69] A. Nehlig, "The neuroprotective effects of cocoa flavanol and its influence on cognitive performance," British Journal of Clinical Pharmacology, vol. 75, no.3, pp.716-727, 2013.

[70] M. Rossi, F. Caruso, L. Kwok et al., "Protection by extra virgin olive oil against oxidative stress in vitro and in vivo. Chemical and biological studies on the health benefits due to a major component of the Mediterranean diet," PLoS One, vol. 12, no. 12, article e0189341, 2017.

[71] S. Rigacci and M. Stefani, "Nutraceutical properties of olive oil polyphenols. An itinerary from cultured cells through animal models to humans," International Journal of Molecular Sciences, vol. 17, no. 6, p. 843, 2016.

[72] M. Martucci, R. Ostan, F. Biondi et al., "Mediterranean diet and inflammaging within the hormesis paradigm," Nutrition Reviews, vol. 75, no. 6, pp. 442-455, 2017.
[73] M. Martínez-Huélamo, J. Rodríguez-Morató, A. Boronat, and R. de la Torre, "Modulation of Nrf2 by olive oil and wine polyphenols and neuroprotection," Antioxidants, vol. 6, no. 4, p. 73, 2017.

[74] H. Zrelli, M. Matsuoka, S. Kitazaki et al., "Hydroxytyrosol induces proliferation and cytoprotection against oxidative injury in vascular endothelial cells: role of Nrf2 activation and HO-1 induction," Journal of Agricultural and Food Chemistry, vol. 59, no. 9, pp. 4473-4482, 2011.

[75] K. Ono, M. Hirohata, and M. Yamada, "Ferulic acid destabilizes preformed $\beta$-amyloid fibrils in vitro," Biochemical and Biophysical Research Communications, vol. 336, no. 2, pp. 444-449, 2005.

[76] S. Layé, A. Nadjar, C. Joffre, and R. P. Bazinet, "Anti-inflammatory effects of omega-3 fatty acids in the brain: physiological mechanisms and relevance to pharmacology," Pharmacol ogical Reviews, vol. 70, no. 1, pp. 12-38, 2018.

[77] T. Kavanagh, P. E. Lonergan, and M. A. Lynch, "Eicosapentaenoic acid and gamma-linolenic acid increase hippocampal concentrations of IL-4 and IL-10 and abrogate lipopolysaccharide -induced inhibition of long-term potentiate on,"Prostaglandins, Leukotrienes and Essential Fatty Acids, vol. 70, no. 4, pp. 391-397, 2004.

[78] E. Teng, K. Taylor, T. Bilousova et al., "Dietary DHA supplementation in an APP/PS1 transgenic rat model of $\mathrm{AD}$ reduces behavioral and $A \beta$ pathology and modulates $A \beta$ oligomerization," Neurobiology of Disease, vol. 82, pp. 552-560, 2015

[79] A. B. Segarra, J. I. Ruiz-Sanz, M. B. Ruiz-Larrea et al., "The profile of fatty acids in frontal cortex of rats depends on the type of fat used in the diet and correlates with neuropeptidase activities," Hormone and Metabolic Research, vol. 43, no. 2,pp. 86-91, 2011.

[80] C. Q. Li, Q. Zheng, Q. Wang, and Q. P. Zeng, "Biotic/abiotic stress-driven Alzheimer's disease," Frontiers in Cellular Neuroscience, vol. 10, p. 269, 2016.

[81] Y. Kobayashi, H. Sugahara, K. Shimada et al., "Therapeutic potential of Bifidobacterium breve strain A1 for preventing cognitive impairment in Alzheimer's disease," Scientific Reports, vol. 7, no. 1, p. 13510, 2017.

[82] L. Bonfili, V. Cecarini, S. Berardi et al., "Microbiota modulation counteracts Alzheimer's disease progression influencing neuronal proteolysis and gut hormones plasma levels," Scientific Reports, vol. 7, no. 1, article 2426, 2017.

[83] E. E. Fröhlich, A. Farzi, R. Mayerhofer et al., "Cognitive impairment by antibiotic-induced gut dysbiosis: analysis of gut microbiota-brain 
communication," Brain, Behavior, and Immunity, vol. 56, pp. 140-155, 2016.

[84] M. J. Claesson, I. B. Jeffery, S. Conde et al., "Gut microbiota composition correlates with diet and health in the elderly," Nature, vol. 488, no. 7410, pp. 178-184, 2012

[85] R. Molteni, R. J. Barnard, Z. Ying, C. K. Roberts, and F. Gomez-Pinilla, "A high-fat, refined sugar diet reduces hippocampal brainderived neurotrophic factor, neuronal plasticity, and learning," Neuroscience, vol. 112, no. 4, pp. 803-814, 2002.

[86] M. Fotuhi, P. Mohassel, and K. Yaffe, "Fish consumption, long-chain omega-3 fatty acids and risk of cognitive decline or Alzheimer disease: a complex association," Nature Clinical Practice Neurology, vol. 5, no. 3, pp. 140-152, 2009.

[87] A. Granzotto and P. Zatta, "Resveratrol and Alzheimer's disease: message in a bottle on red wine and cognition," Frontiers in Aging Neuroscience, vol. 6, p. 95, 2014.

[88] Matthews FE, Arthur A, Barnes LE, Bond J, Jagger C, Robinson L, Brayne C; on behalf of the Medical Research Council Cognitive Function and Ageing Collaboration (2013) A two-decade comparison of prevalence of dementia in individuals aged 65 years and older from three geographical areas of England: Results of the Cognitive Function and Ageing Study I and II. Lancet 382, 1405-1412.

[89] Schrijvers EM, Verhaaren BF, Koudstaal PJ, Hofman A, Ikram MA, Breteler MM (2012) Is dementia incidence declining?: Trends in dementia incidence since 1990 in the Rotterdam Study. Neurology 78, 1456-1463.

[90] Qiu C, von Strauss E, Ba“ckman L, Winblad B, Fratiglioni L (2013) Twenty-year changes in dementia occurrence suggest decreasing incidence in central Stockholm, Sweden. Neurology 80, 1888-1894.

[91] Munoz-Garcia, M. I., Toledo, E., Razquin, C., Dominguez, L. J., Maragarone, D., MartinezGonzalez, J., \& Martinez-Gonzalez, M. A. (20 19). "A priori" Dietary Patterns and Cognitive Function in the SUN Project. Neuroepid emiology, 1-13.doi:10.1159/000502608.

[92] Van den Brink, A. C., Brouwer-Brolsma, E. M., Berendsen, A. A. M., \& van de Rest, O. (2019). The Mediterranean, Dietary Approaches to Stop
Hypertension (DASH), and MediterraneanDASH Intervention for Neurodegenerative Delay (MIND) Diets Are Associated with Less Cognitive Decline and a Lower Risk of Alzheimer's Disease-A Review. Advances in Nutrition. doi:10.1093/advances/nmz054.

[93] Adjibade, M., Assmann, K. E., Julia, C., Galan, P., Hercberg, S., \& Kesse-Guyot, E. (2019). Prospective association between adherence to the MIND diet and subjective memory complaints in the French NutriNet-Santé cohort. Journal of Neurology. doi:10.1007/s00415-01909218-y.

[94] Chen, X., Maguire, B., Brodaty, H., \& O’Leary, F. (2019). Dietary Patterns and Cognitive Health in Older Adults: A Systematic Review. Journal of Alzheimer's Disease, 67(2), 583-619. doi:10.3233/jad-180468.

[95] Gardener, S. L., \& Rainey-Smith, S. R. (2018). The Role of Nutrition in Cognitive Function and Brain Ageing in the Elderly. Current Nutr ition Reports. doi:10.1007/s13668-018-0229-y.

[96] Pistollato, F., Iglesias, R. C., Ruiz, R., Aparicio, S., Crespo, J., Lopez, L. D. Battino, M. (2018). Nutritional patterns associated with the maintenance of neurocognitive functions and the risk of dementia and Alzheimer's disease: A focus on human studies. Pharmacological Research, 131, 32-43. doi:10.1016/j. phrs.2018. 03.012.

[97] Berendsen, A. M., Kang, J. H., Feskens, E. J. M., de Groot, C. P. G. M., Grodstein, F., \& van de Rest, O. (2017). Association of long-term adhe rence to the mind diet with cognitive function and cognitive decline in American women. The Journal of Nutrition, Health \& Aging, 22(2), 222-229. doi:10.1007/s12603-017-09 09-0.

[98] L. Cherian, Y. Wang, K. Fakuda, S. Leurgans, N. Aggarwal, M. Morris, Mediterranean-Dash Intervention for Neurodegenerative Delay (MIND) Diet Slows Cognitive Decline After Stroke. The Journal of Prevention of Alzheimer's Disease - JPAD,Volume 6, Num berhttp://dx.doi.org/10.14283/jpad.2019. 28 .

[99] Agarwal, P., Wang, Y., Buchman, A. S., Holland, T. M., Bennett, D. A., \& Morris, M. C. (2018). Mind Diet Associated with Reduced Incidence and Delayed Progression of Parkinsonism in Old Age. The Journal of Nutrition, Health \& Aging. doi:10.1007/s1260 3-018-1094-5.

Citation: Rajib Dutta, Role of Mind Diet in Preventing Dementia and Alzheimers Disease. ARC Journal of Neuroscience. 2019; 4(3):1-8. doi: dx.doi.org/10.20431/2456-057X 0403001.

Copyright: (C) 2019 Authors. This is an open-access article distributed under the terms of the Creative Commons Attribution License, which permits unrestricted use, distribution, and reproduction in any medium, provided the original author and source are credited. 